OPEN ACCESS

Edited by:

Malgorzata Gabriela Wasniewska,

University of Messina, Italy

Reviewed by:

Mariella Valenzise,

University of Messina, Italy

Mariacarolina Salerno,

University of Naples Federico II, Italy

*Correspondence: Yardena Tenenbaum-Rakover rakover_y@clalit.org.il; yardenaten@gmail.com

Specialty section This article was submitted to Pediatric Endocrinology, a section of the journal Frontiers in Endocrinology

Received: 15 March 2020 Accepted: 23 April 2020

Published: 05 June 2020

Citation:

Admoni $O$, Rath S, Almagor $T$, Elias-Assad G and Tenenbaum-Rakover Y (2020) Long-Term Follow-Up and Outcomes

of Autoimmune Thyroiditis in Childhood. Front. Endocrinol. 11:309. doi: 10.3389/fendo.2020.00309

\section{Long-Term Follow-Up and Outcomes of Autoimmune Thyroiditis in Childhood}

\author{
Osnat Admoni ${ }^{1}$, Shoshana Rath ${ }^{1}$, Tal Almagor ${ }^{1,2}$, Ghadir Elias-Assad ${ }^{1,2}$ and \\ Yardena Tenenbaum-Rakover ${ }^{1,2 *}$ \\ ${ }^{1}$ Pediatric Endocrine Institute, Ha'Emek Medical Center, Afula, Israel, ${ }^{2}$ Rappaport Faculty of Medicine, Technion Institute of \\ Technology, Haifa, Israel
}

Background: Autoimmune thyroiditis (AIT) is the most common cause of acquired hypothyroidism in children. The natural outcome of AIT in childhood has been reported previously however follow-up duration is generally short and results variable.

Objectives: To characterize clinical and biochemical findings at presentation of AIT, evaluate long-term outcomes and assess which factors at presentation predict evolution over time.

Study cohort: 201 children under 18 years of age at presentation (82\% female) were enrolled. Subjects were divided into five subgroups according to thyroid stimulating hormone (TSH) level at referral.

Results: Mean follow-up was 8.1 years (range 0-29 years). At presentation, 34\% of patients had overt hypothyroidism, 32\% subclinical hypothyroidism (SCH), 16\% compensated hypothyroidism, 14\% were euthyroid, and 3.7\% had Hashitoxicosis. Children with overt hypothyroidism were younger (10.6 vs. 13.2 years) and had higher thyroid peroxidase antibody titers. At the time of the study, levothyroxine $\left(L T_{4}\right)$ therapy was required in $26 \%$ of children who were euthyroid at presentation, $56 \%$ of $\mathrm{SCH}$ patients, $83-84 \%$ of those with $\mathrm{TSH}$ above $10 \mathrm{mlU} / \mathrm{L}$, and $57 \%$ of those with Hashitoxicosis. Over the years, $16 \%$ of children presenting with overt hypothyroidism stopped therapy. Free $T_{4}$ at presentation was the only predictor of outcome over time.

Conclusions: Our findings suggest that only $26 \%$ children who were euthyroid at presentation developed hypothyroidism, whereas over $50 \%$ of those with $\mathrm{SCH}$ went on to require treatment. Of those presenting with overt hypothyroidism, 16\% recovered with time. The only predictive parameter for $\mathrm{LT}_{4}$ therapy at the end of the study was free $\mathrm{T}_{4}$ levels at presentation. Long-term follow-up is required to determine ongoing therapy needs and screen for additional autoimmune diseases.

Keywords: autoimmune thyroiditis (AIT), Hashimoto's thyroiditis, thyroid autoantibodies, goiter, Hashitoxicosis 


\section{INTRODUCTION}

Autoimmune thyroiditis (AIT), also known as Hashimoto's thyroiditis, is the most common cause of acquired hypothyroidism in childhood, with a prevalence of 1 to $3 \%$, peaking during adolescence (1-3). There is a female predominance, with a female-to-male ratio of $4-8: 1$ (2). AIT is characterized by thyroid destruction due to an autoimmunemediated process, resulting in gradual thyroid failure with or without goiter. The diagnosis of AIT is suggested by the presence of anti-thyroid antibodies against peroxidase (TPOAb) and/or thyroglobulin (TGAb) and by a typical hypo-echogenic and heterogeneous ultrasound pattern. Children are commonly referred for endocrine evaluation due to thyroid enlargement or on the basis of abnormal thyroid function results discovered as part of a medical workup for variable complaints (often unrelated to thyroid dysfunction) or for positive family history of AIT. At the time of diagnosis, thyroid function in children may be variable ranging from euthyroidism $(52.1 \%)$, to overt $(22.2 \%)$ or subclinical hypothyroidism (SCH) $(19.2 \%)$ or, more rarely to either subclinical or overt hyperthyroidism (6.5\%) (4).

Predictive factors for progression from euthyroidism or $\mathrm{SCH}$ to overt hypothyroidism, or for recovery from hypothyroidism over time, have been investigated in some studies, with variable results (3-19). Some of the studies included a small number of patients $(5,7,8,12,19)$ and were of short duration $(9,10,13$, 16). Moreover, the definition of $\mathrm{SCH}$, as well as indications for levothyroxine $\left(\mathrm{LT}_{4}\right)$ supplemental therapy, differ among authors (15) and include goiter shrinkage in some instances (20). de Vries et al. (18) reported that almost all of their patients required $\mathrm{LT}_{4}$ treatment either at referral or during follow-up. Conversely, other studies suggested favorable outcomes for patients who were euthyroid or had SCH at referral $(6-9,11,16)$, whereas only $25-50 \%$ of those with initial thyroid dysfunction experienced normalization of thyroid function over time $(1,8,9,12-14,17)$.

Predictive factors for the development of overt hypothyroidism included: elevated TGAb and the presence of goiter (6), as well as elevated TPOAb, elevated thyroid stimulating hormone (TSH) and the presence of celiac disease (16).

The objectives of this retrospective study were to evaluate the long-outcomes of AIT in children with variable thyroid function at presentation, to evaluate the prevalence of euthyroid and/or SCH patients developing overt hypothyroidism, and the prevalence of patients with overt hypothyroidism becoming euthyroid after long-term treatment, and to identify predictive factors of long-term outcomes.

\section{SUBJECTS AND METHODS}

\section{Study Cohort}

We enrolled 201 subjects in the study, all under 18 years of age at diagnosis. They were followed up on a 6-monthly basis at Ha'Emek Medical Center or in outpatient clinics affiliated with the hospital. All patients had positive TGAb and/or TPOAb. Most subjects also had at least one of the following: abnormal thyroid function, enlarged thyroid gland, morphological changes on thyroid ultrasound. Patients were referred for evaluation by a pediatric endocrinologist due to one or more of the following: abnormal thyroid functions, elevated thyroid antibodies, presence of goiter and various complaints that were related to abnormal thyroid function. Patients with diabetes mellitus type 1 (DMT1) diagnosed prior to the diagnosis of AIT, and those with Down or Turner syndromes, were excluded from the study. $\mathrm{LT}_{4}$ supplemental therapy was initiated in overt hypothyroidism, when TSH levels were above $10 \mathrm{mIU} / \mathrm{L}$, and in a few individuals with $\mathrm{TSH}<10 \mathrm{mIU} / \mathrm{L}$ for the purpose of goiter shrinkage. $\mathrm{LT}_{4}$ dose was adjusted to maintain TSH concentrations within a normal range. Data were collected retrospectively from computerized medical files and included: clinical findings and thyroid function at presentation, during follow-up and at the last visit; $\mathrm{LT}_{4}$ therapy initiation; additional autoimmune diseases and family history of autoimmune and thyroid diseases.

\section{Hormone Analysis}

Serum TSH (normal range $0.4-4.2 \mathrm{mIU} / \mathrm{L}$ ) and free thyroxine $\left(\mathrm{FT}_{4}\right.$; normal range $\left.10-20 \mathrm{pmol} / \mathrm{L}\right)$ concentrations were measured by direct automated chemiluminescent immunoradiometric assays using ADVIA Centaur (Bayer Corporation, Tarrytown, NY). TGAb and TPOAb were measured by direct automated chemiluminescent immunoradiometric assay using Immulite 2000 (Siemens, Llanberis, Gwynedd, UK). TGAb and TPOAb were considered positive above $35 \mathrm{U} / \mathrm{mL}$.

\section{Subgroups}

Patients were classified into five subgroups according to TSH level at presentation: (i) hyperthyroid (TSH $<0.03 \mathrm{mIU} / \mathrm{L}$ and $\mathrm{FT}_{4} \geq 20 \mathrm{pmol} / \mathrm{L}$ ); (ii) euthyroid (TSH $0.4-4.2 \mathrm{mIU} / \mathrm{L}$ and $\mathrm{FT}_{4}$ 10-20 pmol/L); (iii) $\mathrm{SCH}$ (TSH 4.3-10 mIU/L); (iv) compensated hypothyroid (TSH $10.1-20 \mathrm{mIU} / \mathrm{L}$ with normal $\mathrm{FT}_{4}$ ); (v) hypothyroid (TSH $>20 \mathrm{mIU} / \mathrm{L}$ ). Since our practice is to initiate $\mathrm{LT}_{4}$ therapy in patients with TSH above $10 \mathrm{mIU} / \mathrm{L}$ even if $\mathrm{FT}_{4}$ is within the normal range, we divided patients into two subgroups according to their TSH levels: those with TSH 4.3-10 mIU/L were defined as SCH while those with TSH above $10 \mathrm{mIU} / \mathrm{L}$ and $\mathrm{FT}_{4}$ above $10 \mathrm{pmol} / \mathrm{L}$ were defined as compensated SCH.

\section{Statistical Analysis}

Statistical analyses were performed with SAS v9.4 statistical software package (Cary, NC). Study groups were compared by Kruskal-Wallis test (continuous variables) and Chi-square or Fisher's Exact Test (categorical variables). Pairwise comparisons were made using Wilcoxon two-sample tests and Chi-square or Fisher's exact test for continuous and categorical variables, respectively, using Bonferroni correction. Univariate analyses were performed for the study outcome: $\mathrm{LT}_{4}$ therapy at the end of the study follow-up. Stepwise logistic regression was used for multivariable analysis to establish independent predictors for $\mathrm{LT}_{4}$ therapy at the end of the follow-up period. Significance was set at $p<0.05$.

This study was approved by the Ethics Committee of Ha'Emek Medical Center. 


\section{RESULTS}

The study population consisted of 201 subjects (female-tomale ratio of $4.5: 1$ ) with mean age of $11.7 \pm 3.4$ years (range 2.25-17.75 years). Reasons for referral were goiter or thyroid dysfunction and/or increased thyroid autoantibodies identified during a work-up performed for various other complaints (hair loss, obesity, weight gain, short stature, pubertal delay, fatigue and headaches).

Mean TSH at presentation was $55 \pm 145 \mathrm{mIU} / \mathrm{L}$ (range $0.02-1,225$ ) and $\mathrm{FT}_{4} 12.7 \pm 6.7 \mathrm{pmol} / \mathrm{L}$ (range 1.2-67). TSH at presentation, was undetectable in $3.7 \%$ of subjects, within the normal range in $14 \%$, slightly increased in $32 \%$, and elevated ( $>10 \mathrm{mIU} / \mathrm{L}$ ) in $50 \%$. $\mathrm{FT}_{4}$ was below the normal range in $29 \%$ of patients. TGAb was positive in $83 \%$ and TPOAb in $95 \%$ of cases. Thyroid gland enlargement was identified in $66 \%$ of patients by neck examination.

Fifty-five patients (28\%) had an additional autoimmune disease diagnosed either before or after AIT diagnosis. Autoimmune comorbidities included celiac disease (15 patients), pernicious anemia (nine patients), rheumatic diseases (six patients), vitiligo (five patients), DMT1 (three patients), alopecia areata (three patients) and others (14 patients). Positive family history of thyroid diseases was reported in 80 patients (40\%), including AIT, Graves' disease, papillary thyroid carcinoma, and multinodular goiter. Follow-up duration was 8.1 years (range 0-29).

The cohort was divided into five subgroups according to TSH level at diagnosis: hyperthyroid (seven patients), euthyroid (27 patients), SCH (60 patients), compensated SCH (30 patients), and hypothyroid (64 patients). Clinical and biochemical findings in the different subgroups are presented in Table 1. Subjects with overt hypothyroidism were younger than euthyroid subjects $(p=0.0011)$. As expected $\mathrm{FT}_{4}$ levels were significantly lower $(p<0.0001)$ in overtly hypothyroid children compared to those with $\mathrm{SCH}$ and euthyroid patients. TGAb levels at presentation did not differ between groups, but TPOAb values were higher in the overtly hypothyroid group than in the euthyroid group $(p=0.0004)$. Gender did not differ between groups.

At $\mathrm{LT}_{4}$ initiation, patients with overt hypothyroidism were significantly younger than those in the euthyroid, $\mathrm{SCH}$, and hyperthyroid groups $(p=0.0016)$ and had higher TSH and lower $\mathrm{FT}_{4}$ levels.

During the follow-up period, $\mathrm{LT}_{4}$ therapy was initiated in $100 \%$ of subjects presenting with overt or compensated hypothyroidism; however, at the time of the study, 5 (16\%) and $11(17 \%)$ of those patients, respectively, no longer required treatment.

No differences in variables at presentation were found between patients who were off therapy compared to those who required therapy at the end of the follow-up period. As for the other groups, three patients (43\%) presenting with hyperthyroidism, 27 patients (44\%) with SCH and 20 (74\%) of the euthyroid group did not receive treatment. Follow-up duration, age at last visit and thyroid autoantibodies at the time of the study did not differ among groups (Table 1).
A comparison of thyroid antibody levels in the whole cohort revealed lower levels at the study endpoint compared to levels at the time of referral. Univariate analysis revealed that patients who underwent therapy at presentation were younger (11.4 vs. 12.7 years, $p=0.036$ ), had higher TSH (73 vs. $5.0 \mathrm{mIU} / \mathrm{L}, p<$ $0.0001)$, lower $\mathrm{FT}_{4}(11.7$ vs. $15.8 \mathrm{pmol} / \mathrm{L}, p<0.0001)$ and higher TPOAb (920 vs. $521 \mathrm{U} / \mathrm{mL}, p=0.002)$. Gender and TGAb did not differ.

At the end of the study, 122 patients were receiving $\mathrm{LT}_{4}$ therapy, while 64 were not. Looking for factors at presentation predictive of $\mathrm{LT}_{4}$ therapy at the end of the follow-up period, multivariable logistic regression performed for age, gender, TSH, $\mathrm{FT}_{4}$, TPOAb, TGAb, goiter, familial history of thyroid disease and additional autoimmune diseases revealed that only $\mathrm{FT}_{4}$ level at presentation was predictive for a future need for $\mathrm{LT}_{4}$ therapy.

\section{DISCUSSION}

In this study, we examined clinical and laboratory characteristics at presentation of AIT in children and adolescents and its natural progression. We found that about $75 \%$ of children euthyroid at diagnosis remained in this stable condition over time, whereas only $16 \%$ of those presenting with overt hypothyroidism attained remission.

The primary cause for referral to our service was thyroid function abnormality or elevated autoantibodies (68\%) and the most prevalent complaint was thyroid enlargement (32\%). Interestingly, goiter was identified in $66 \%$ of the patients on physical examination at presentation, in keeping with the high prevalence of goiter reported in previous studies $(10,11)$.

The prevalence of AIT is about 1.2 to $3 \%$, with $87 \%$ of cases asymptomatic at presentation and spontaneous resolution occurring in $50 \%(1,2)$. The benign evolution of euthyroid AIT in children has been reported in several studies (7-9, 12-14). Our finding, that only $26 \%$ of children who were euthyroid at presentation developed hypothyroidism during the followup period is consistent with these data, suggesting that most euthyroid children remain disease free over time. On the other hand, in the study of de Vries et al. (18) almost all patients were treated with $\mathrm{LT}_{4}$ at referral or during follow-up, however, their data suggested that appropriately monitored $\mathrm{LT}_{4}$ therapy, even in euthyroid children, does not appear to be harmful.

$\mathrm{SCH}$ is characterized by serum TSH levels between 4.2 and $10 \mathrm{mIU} / \mathrm{L}$ with normal $\mathrm{FT}_{4}$ levels. In the presence of thyroid autoantibodies, the diagnosis of AIT is most likely (20). Lazar et al. (21) demonstrated spontaneous normalization of TSH values in most patients with $\mathrm{SCH}$ without supplemental therapy. Female gender and initial TSH above $7 \mathrm{mIU} / \mathrm{L}$ were predictors of sustained highly elevated TSH. In this study however, the cohort was not limited to subjects with AIT. The risk of deterioration of thyroid status over time is higher in AIT compared to idiopathic SCH (53 vs. 11\%) $(5,14,15)$, as observed in our study, where $56 \%$ of those with SCH required treatment over time.

The presence of additional autoimmune diseases $(6,15,16)$ and of genetic syndrome such as Turner and Down syndromes 
TABLE 1 | Comparison of clinical and biochemical parameters in the five subgroups.

\begin{tabular}{|c|c|c|c|c|c|c|}
\hline At diagnosis & Hyperthyroidism & Euthyroidism & $\mathrm{SCH}$ & Compensated SCH & Hypothyroidism & $P$-value \\
\hline Hormonal status & $\begin{array}{c}\mathrm{TSH}<0.03 \mathrm{mlU} / \mathrm{L} \\
\mathrm{FT}_{4}>20 \mathrm{pmol} / \mathrm{L}\end{array}$ & $\begin{array}{l}\mathrm{TSH} \text { 0.4-4.2 mIU/L } \\
\mathrm{FT}_{4} \text { 10-20 pmol/L }\end{array}$ & TSH 4.3-10 mlU/L & TSH 10.1-20 mlU/L & $\mathrm{TSH}>20 \mathrm{mlU} / \mathrm{L}$ & \\
\hline No. of patients & $7(3.7 \%)$ & 27 (14.3\%) & $60(32 \%)$ & $30(16 \%)$ & $64(34 \%)$ & \\
\hline Gender (F:M) \% male & $6: 1(14 \%)$ & $25: 2(8 \%)$ & $43: 17$ (28\%) & $22: 8(27 \%)$ & $57: 7(11 \%)$ & \\
\hline \multicolumn{7}{|l|}{ At presentation } \\
\hline Age (years) & $\begin{array}{l}13.8 \pm 2.6 \\
(8.2-16.2)\end{array}$ & $\begin{array}{l}13.2 \pm 3.0 \\
(7.7-17.8)\end{array}$ & $\begin{array}{l}11.5 \pm 2.9 \\
(5.2-17.5)\end{array}$ & $\begin{array}{l}12.0 \pm 3.8 \\
(4.5-17.6)\end{array}$ & $\begin{array}{l}10.6 \pm 3.4 \\
(2.3-17.6)\end{array}$ & 0.005 \\
\hline TSH (mlU/L) & $\begin{array}{l}0.03 \pm 0.01 \\
(0.02-0.04)\end{array}$ & $\begin{array}{l}2.4 \pm 1.0 \\
(0.9-4.1)\end{array}$ & $\begin{array}{l}7.1 \pm 1.7 \\
(4.4-9.8)\end{array}$ & $\begin{array}{l}13.5 \pm 3.0 \\
(10.1-19.6)\end{array}$ & $\begin{array}{c}152.1 \pm 226 \\
(21.7-1224.7)\end{array}$ & $<0.0001$ \\
\hline $\mathrm{FT}_{4}(\mathrm{pmol} / \mathrm{L})$ & $\begin{array}{l}34.5 \pm 16.1 \\
(19.6-67.0)\end{array}$ & $\begin{array}{c}14.8 \pm 2.2 \\
(11.3-19.2)\end{array}$ & $\begin{array}{l}14.1 \pm 2.3 \\
(9.4-19.8)\end{array}$ & $\begin{array}{l}13.3 \pm 1.7 \\
(10.3-17.1)\end{array}$ & $\begin{array}{l}7.8 \pm 3.1 \\
(1.2-14.2)\end{array}$ & $<0.0001$ \\
\hline TPOAb (U/mL) & $\begin{array}{l}681 \pm 448 \\
(65-1,000)\end{array}$ & $\begin{array}{l}397 \pm 321 \\
(26-1,000)\end{array}$ & $\begin{array}{c}721 \pm 1005 \\
(10-5,730)\end{array}$ & $\begin{array}{l}645 \pm 397 \\
(35-1,000)\end{array}$ & $\begin{array}{c}1,195 \pm 2,010 \\
(11-13,372)\end{array}$ & 0.01 \\
\hline TGAb (U/mL) & $\begin{array}{l}357 \pm 408 \\
(30-1,136)\end{array}$ & $\begin{array}{l}451 \pm 723 \\
(28-3,000)\end{array}$ & $\begin{array}{l}485 \pm 868 \\
(20-3,000)\end{array}$ & $\begin{array}{c}529 \pm 1,092 \\
(25-4,284)\end{array}$ & $\begin{array}{c}876 \pm 1,463 \\
(30-6,500)\end{array}$ & 0.5 \\
\hline \multicolumn{7}{|l|}{ At $\mathrm{LT}_{4}$ therapy initiation } \\
\hline Age (years) & $\begin{array}{l}17.4 \pm 4.5 \\
(12.5-23.3)\end{array}$ & $\begin{array}{l}14.8 \pm 3.9 \\
(9.2-22.4)\end{array}$ & $\begin{array}{l}13.5 \pm 3.7 \\
(6.0-21.8)\end{array}$ & $\begin{array}{l}12.8 \pm 4.5 \\
(5.0-23.3)\end{array}$ & $\begin{array}{l}10.6 \pm 3.4 \\
(2.3-17.8)\end{array}$ & 0.0001 \\
\hline Years between diagnosis and $\mathrm{LT}_{4}$ therapy & $\begin{array}{l}4.4 \pm 3.6 \\
(1.07-9.5)\end{array}$ & $\begin{array}{c}2.7 \pm 2.1 \\
(0-8.1)\end{array}$ & $\begin{array}{c}1.4 \pm 2.2 \\
(0-11.3)\end{array}$ & $\begin{array}{c}0.27 \pm 1.3 \\
(0-12.4)\end{array}$ & $\begin{array}{l}0.05 \pm 0.271 \\
(0-2.17)\end{array}$ & $<0.0001$ \\
\hline $\begin{array}{l}\mathrm{TSH}_{\text {at }} \mathrm{LT}_{4} \text { initiation } \\
\text { (mIU/L) }\end{array}$ & $\begin{array}{c}47.6 \pm 69 \\
(6.4-150.6)\end{array}$ & $\begin{array}{c}36.0 \pm 49.2 \\
(0.9-132)\end{array}$ & $\begin{array}{l}17.2 \pm 28.0 \\
(5.0-150.4)\end{array}$ & $\begin{array}{c}21.9 \pm 29.1 \\
(5.5-150)\end{array}$ & $\begin{array}{c}153.1 \pm 2,283 \\
(5.3-1,223)\end{array}$ & $<0.0001$ \\
\hline $\mathrm{FT}_{4}$ at $\mathrm{LT}_{4}$ initiation $(\mathrm{pmol} / \mathrm{L})$ & $\begin{array}{l}10.4 \pm 6.9 \\
(6.9-14.4)\end{array}$ & $\begin{array}{l}11.4 \pm 4.3 \\
(3.4-16.4)\end{array}$ & $\begin{array}{l}13.2 \pm 2.4 \\
(8.8-19.8)\end{array}$ & $\begin{array}{l}13.0 \pm 2.7 \\
(4.4-17.8)\end{array}$ & $\begin{array}{l}7.7 \pm 3.1 \\
(1.2-13.7)\end{array}$ & $<0.0001$ \\
\hline \multicolumn{7}{|l|}{ Time of study } \\
\hline Age (years) & $\begin{array}{c}21.6 \pm 6.7 \\
(15-33)\end{array}$ & $\begin{array}{l}19.5 \pm 6.3 \\
(8.1-31.1)\end{array}$ & $\begin{array}{l}18.7 \pm 5.5 \\
(9.4-31.0)\end{array}$ & $\begin{array}{c}20.0 \pm 5.9 \\
(9.3-35.0)\end{array}$ & $\begin{array}{l}18.9 \pm 5.8 \\
(5.1-33.0)\end{array}$ & 0.76 \\
\hline Follow-up duration (years) & $\begin{array}{c}8.0 \pm 6.5 \\
(0.4-19)\end{array}$ & $\begin{array}{c}6.4 \pm 6.1 \\
(0-20.8)\end{array}$ & $\begin{array}{c}7.6 \pm 6.1 \\
(0-20.8)\end{array}$ & $\begin{array}{l}8.7 \pm 6.7 \\
(0.1-29.4)\end{array}$ & $\begin{array}{l}9.3 \pm 5.5 \\
(0.8-22.0)\end{array}$ & 0.11 \\
\hline TSH (mIU/L) & $\begin{array}{c}5.2 \pm 4.3 \\
(0.02-11.6)\end{array}$ & $\begin{array}{c}3.4 \pm 3.4 \\
(0.36-18.6)\end{array}$ & $\begin{array}{l}6.4 \pm 3.4 \\
(0.4-18.6)\end{array}$ & $\begin{array}{c}15.1 \pm 53.3 \\
(0.3-296)\end{array}$ & $\begin{array}{c}13.1 \pm 31.8 \\
(0.04-196)\end{array}$ & 0.15 \\
\hline $\mathrm{FT}_{4}(\mathrm{pmol} / \mathrm{L})$ & $\begin{array}{c}14.9 \pm 8.4 \\
(12.3-28.4)\end{array}$ & $\begin{array}{l}14.9 \pm 9.9 \\
(9.9-19.9)\end{array}$ & $\begin{array}{l}14.9 \pm 7.2 \\
(9.9-19.9)\end{array}$ & $\begin{array}{c}15.7 \pm 6.4 \\
(11.4-21.1)\end{array}$ & $\begin{array}{l}14.9 \pm 5.6 \\
(2.2-28.4)\end{array}$ & 0.9 \\
\hline TGAb (U/mL) & $\begin{array}{l}460 \pm 599 \\
(34-1,255)\end{array}$ & $\begin{array}{l}411 \pm 833 \\
(30-3,000)\end{array}$ & $\begin{array}{l}540 \pm 980 \\
(20-3,000)\end{array}$ & $\begin{array}{c}1,655 \pm 4,363 \\
(39-15,907)\end{array}$ & $\begin{array}{l}443 \pm 565 \\
(21-3,000)\end{array}$ & 0.58 \\
\hline TPOAb (U/mL) & $\begin{array}{l}515 \pm 456 \\
(76-1,000)\end{array}$ & $\begin{array}{l}390 \pm 291 \\
(24-1,000)\end{array}$ & $\begin{array}{l}692 \pm 866 \\
(11-1,000)\end{array}$ & $\begin{array}{l}632 \pm 380 \\
(29-1,300)\end{array}$ & $\begin{array}{l}552 \pm 535 \\
(10-3,000)\end{array}$ & 0.59 \\
\hline $\begin{array}{l}\text { No of patients undergoing } \mathrm{LT}_{4} \text { therapy at time } \\
\text { of study (\%) }\end{array}$ & 4 (57\%) & 7 (26\%) & 33 (56\%) & 25 (83\%) & 53 (84\%) & $<0.0001$ \\
\hline
\end{tabular}

TSH normal range 0.4-4.2 $\mathrm{m} / \mathrm{U} / \mathrm{L}$.

$\mathrm{FT}_{4}$ normal range 10-20 $\mathrm{pmol} / \mathrm{L}$.

SCH, sub clinical hypothyroidism, TPOAb, TPO abs; TGAb, Thyroglobulin antibodies.

$(14,15)$ has been shown to increase the risk of deterioration in thyroid function. In our study, therefore, patients with these syndromes were excluded, as were children with DMT1 in whom thyroid seropositive antibodies were detected after the diagnosis of diabetes mellitus, as the natural history of AIT in these children differs (22).

Amongst our cohort, a small number of patients were treated with $\mathrm{LT}_{4}$ therapy for goiter shrinkage despite TSH levels below $10 \mathrm{mIU} / \mathrm{L}$, an approach that is suggested in a few studies $(23,24)$. Even though $\mathrm{LT}_{4}$ therapy has been shown to reduce thyroid autoantibodies in patients with $\mathrm{SCH}$ and overt hypothyroidism, its beneficial effect on the evolution of thyroid function $(11,25)$, and on metabolic (26) and neurocognitive outcome (27-29) remains uncertain. In the United States, the prevalence of positive thyroid antibodies, in the disease-free population above 12 years of age, is about $10 \%$, it is more prevalent in females and increases with age (30). TPOAb are significantly associated with thyroid function but TGAb are not (30). In our study, elevated TPOAb were associated with initiation of $\mathrm{LT}_{4}$ at presentation, but were not predictive for long-term $\mathrm{LT}_{4}$ treatment, whereas, in our multivariate analysis, only $\mathrm{FT}_{4}$ values at presentation predicted future treatment requirements in children with AIT. 
Normalization of thyroid function over time has been reported to occur in $30-50 \%$ of children presenting with overt hypothyroidism $(8,9)$. In our study, supplemental therapy was initiated in all such patients with remission occurring in only $16 \%$ by the end of the follow-up period. Although this remission rate is lower than that reported in other studies, it suggests that reassessment of thyroid status is important given that $16 \%$ of those with overt autoimmune hypothyroidism may not require lifelong $\mathrm{LT}_{4}$ therapy.

Hyperthyroidism was the presenting symptom in seven patients (3.7\%), with four developing hypothyroidism over time. Although hyperthyroidism is an uncommon presentation of AIT, awareness of this condition is important and should be differentiated from Graves' disease in order to avoid unnecessary suppressive therapy $(3,31)$.

A family history of thyroid disease was present in $40 \%$ of children with AIT, including Hashimoto's thyroiditis, Graves' disease, multinodular goiter and papillary thyroid carcinoma, suggesting a genetic susceptibility to thyroid disease. In addition, other autoimmune diseases were present in $28 \%$ of the cohort. These findings highlight the need for screening patients with AIT for additional autoimmune diseases.

This large, long-term retrospective study adds further information to the controversial issue of the natural history of AIT in childhood. The major limit of this study is its retrospective nature, with variable duration of follow-up among individuals.

In conclusion, this study indicates that $26 \%$ of children with normal thyroid function at presentation develop overt hypothyroidism, over $50 \%$ of those with initial SCH may eventually require $\mathrm{LT}_{4}$ treatment and $16 \%$ of those presenting with overt hypothyroidism may recover over time. $\mathrm{FT}_{4}$ at

\section{REFERENCES}

1. Rallison ML, Dobyns BM, Keating FR, Rall JE, Tyler FH. Occurrence and natural history of chronic lymphocytic thyroiditis in childhood. J Pediatr. (1975) 86:675-82. doi: 10.1016/S0022-3476(75)80350-7

2. Segni M. Disorders of the thyroid gland in infancy, childhood and adolescence. In: Feingold KR, Anawalt B, Boyce A, et al., editors. Endotext. South Dartmouth, MA: MDText.com (2000). Available online at: https:// www.ncbi.nlm.nih.gov/books/NBK278943 (accessed March 18, 2017).

3. Crisafulli G, Gallizzi R, Aversa T, Salzano G, Valenzise M, Wasniewska M, et al. Thyroid function test evolution in children with Hashimoto's thyroiditis is closely conditioned by the biochemical picture at diagnosis. Ital J Pediatr. (2018) 7:22. doi: 10.1186/s13052-018-0461-5

4. Wasniewska M, Corrias A, Salerno M, Mussa A, Capalbo D, Messina MF et al. Thyroid function patterns at Hashimoto's thyroiditis presentation in childhood and adolescence are mainly conditioned by patients' age. Horm Res Paediatr. (2012) 78:232-6. doi: 10.1159/000343815

5. Aversa T, Valenzise M, Corrias A, Salerno M, De Luca F, Mussa A, et al. Underlying Hashimoto's thyroiditis negatively affects the evolution of subclinical hypothyroidism in children irrespective of other concomitant risk factors. Thyroid. (2015) 25:183-7. doi: 10.1089/thy.2014.0235

6. Radetti G, Gottardi E, Bona G, Corrias A, Salardi S, Loche S. Study Group for Thyroid Diseases of the Italian Society for Pediatric Endocrinology and Diabetes (SIEDP/ISPED). The natural history of euthyroid Hashimoto's thyroiditis in children. J Pediatr. (2006) 149:827-32. doi: $10.1016 /$ j.jpeds.2006.08.045 presentation appears to be the only factor predicting evolution of thyroid status. Further long-term studies on large cohorts of patients are needed to better clarify the natural history of AIT and identify prognostic factors for therapeutic intervention.

\section{DATA AVAILABILITY STATEMENT}

The datasets generated for this study are available on request to the corresponding author.

\section{ETHICS STATEMENT}

This study involving human participants was reviewed and approved by Ha'Emek Medical Center Helsinki Comittee. Written informed consent for participation was not provided by the participants' legal guardians/next of kin, nor was written consent required from the local ethics committee since the study was retrospective collecting data from medical files.

\section{AUTHOR CONTRIBUTIONS}

OA collected the data and reviewed and revised the manuscript. TA, SR, and GE-A reviewed and revised the manuscript. YT-R drafted the initial manuscript, designed the study, coordinated and collected the data, and revised the manuscript.

\section{ACKNOWLEDGMENTS}

We thank Naama Schwartz for professional statistical analysis and Camille Vainstein for professional English editing.

7. Fava A, Oliverio R, Giuliano S, Parlato G, Michniewicz A, Indrieri A, et al. Clinical evolution of autoimmune thyroiditis in children and adolescents. Thyroid. (2009) 19:361-7. doi: 10.1089/thy.2008.0239

8. Wang SY, Tung YC, Tsai WY, Lee JS, Hsiao PH. Long-term outcome of hormonal status in Taiwanese children with Hashimoto's thyroiditis. Eur J Pediatr. (2006) 165:481-3. doi: 10.1007/s00431-006-0112-5

9. Demirbilek H, Kandemir N, Gonc EN, Ozon A, Alikasifoglu A. Assessment of thyroid function during the long course of Hashimoto's thyroiditis in children and adolescents. Clin Endocrinol. (2009) 71:451-4. doi: 10.1111/j.1365-2265.2008.03501.x

10. Özen S, Berk Ö, Simşek DG, Darcan S. Clinical course of Hashimoto's thyroiditis and effects of levothyroxine therapy on the clinical course of the disease in children and adolescents. J Clin Res Pediatr Endocrinol. (2011) 3:192-7. doi: 10.4274/jcrpe.425

11. Lee HS, Hwang JS. The natural course of Hashimoto's thyroiditis in children and adolescents. J Pediatr Endocrinol Metab. (2014) 27:807-12. doi: 10.1515/jpem-2013-0373

12. Moore DC. Natural course of "subclinical" hypothyroidism in childhood and adolescence. Arch Pediatr Adolesc Med. (1996) 150:293-7. doi: 10.1001/archpedi.1996.02170280063012

13. Wasniewska M, Salerno M, Cassio A, Corrias A, Aversa T, Zirilli G, et al. Prospective evaluation of the natural course of idiopathic subclinical hypothyroidism in childhood and adolescence. Eur J Endocrinol. (2009) 160:417-21. doi: 10.1530/EJE-08-0625

14. Wasniewska M, Aversa T, Salerno M, Corrias A, Messina MF, Mussa A, et al. Five-year prospective evaluation of thyroid function in girls with subclinical 
mild hypothyroidism of different etiology. Eur J Endocrinol. (2015) 173:801-8. doi: 10.1530/EJE-15-0484

15. Salerno M, Capalbo D, Cerbone M, De Luca F. Subclinical hypothyroidism in childhood - current knowledge and open issues. Nat Rev Endocrinol. (2016) 12:734-46. doi: 10.1038/nrendo.2016.100

16. Radetti G, Maselli M, Buzi F, Corrias A, Mussa A, Cambiaso P, et al. The natural history of the normal/mild elevated TSH serum levels in children and adolescents with Hashimoto's thyroiditis and isolated hyperthyrotropinaemia: a 3-year follow-up. Clin Endocrinol. (2012) 76:394-8. doi: $10.1111 / j .1365-2265.2011 .04251 . x$

17. Aversa T, Corrias A, Salerno M, Tessaris D, Di Mase R, Valenzise M, et al. Five year prospective evaluation of thyroid function test evolution in children with Hashimoto's thyroiditis presenting with either euthyroidism or subclinical hypothyroidism. Thyroid. (2016) 26:1450-6. doi: 10.1089/thy.2016.0080

18. de Vries L, Bulvik S, Phillip M. Chronic autoimmune thyroiditis in children and adolescents: at presentation and during long-term follow-up. Arch Dis Child. (2009) 94:33-7. doi: 10.1136/adc.2007.134841

19. Jaruratanasirikul S, Leethanaporn K, Khuntigij P, Sriplung H. The clinical course of Hashimoto's thyroiditis in children and adolescents: 6 years longitudinal follow-up. J Pediatr Endocrinol Metab. (2001) 14:177-84. doi: 10.1515/JPEM.2001.14.2.177

20. Crisafulli G, Aversa T, Zirilli G, Pajno GB, Corica D, De Luca F, et al. Subclinical hypothyroidism in children: when a replacement hormonal treatment might be advisable. Front Endocrinol. (2019) 10:109. doi: $10.3389 /$ fendo.2019.00109

21. Lazar L, Frumkin RB, Battat E, Lebenthal Y, Phillip M, Meyerovitch J. Natural history of thyroid function tests over 5 years in a large pediatric cohort. J Clin Endocrinol Metab. (2009) 94:1678-82. doi: 10.1210/jc.2008-2615

22. Kordonouri O, Klinghammer A, Lang EB, Grüters-Kieslich A, Grabert M, Holl RW. Thyroid autoimmunity in children and adolescents with type 1 diabetes. Diabetes Care. (2002) 25:1346-50. doi: 10.2337/diacare.25. 8.1346

23. Svensson J, Ericsson UB, Nilsson P, Olsson C, Jonsson B, Lindberg B, et al. Levothyroxine treatment reduces thyroid size in children and adolescents with chronic autoimmune thyroiditis. J Clin Endocrinol Metab. (2006) 91:1729-34. doi: 10.1210/jc.2005-2400

24. Scarpa V, Kousta E, Tertipi A, Vakaki M, Fotinou A, Petrou V, et al. Treatment with thyroxine reduces thyroid volume in euthyroid children and adolescents with chronic autoimmune thyroiditis. Horm Res Paediatr. (2010) 73:61-7. doi: $10.1159 / 000271917$
25. Wasniewska M, Corrias A, Avesta T, Valenzise M, Mussa A, De Marino L, et al. Comparative evaluation of therapy with L-thyroxine versus no treatment in children with idiopathic and mild subclinical hypothyroidism. Horm Res Paediatr. (2012) 77:376-81. doi: 10.1159/000339156

26. Cerbone M, Capalbo D, Wasniewska M, Alfano S, Mattace Raso G, Oliviero $\mathrm{U}$, et al. Effects of L-thyroxine treatment on early markers of atherosclerotic disease in children with subclinical hypothyroidism. Eur J Endocrinol. (2016) 175:11-9. doi: 10.1530/EJE-15-0833

27. Cerbone M, Bravaccio C, Capalbo D, Polizzi M, Wasniewska M, Cioffi D, et al. Linear growth and intellectual outcome in children with long-term idiopathic subclinical hypothyroidism. Eur J Endocrinol. (2011) 164:591-7. doi: 10.1530/EJE-10-0979

28. Capalbo D, Alfano S, Polizzi M, Di Mase R, Improda N, Esposito A, et al. Cognitive function in children with idiopathic subclinical hypothyroidism: effects of 2 years of levothyroxine therapy. J Clin Endocrinol Metab. (2020) 105:dgaa046. doi: 10.1210/clinem/dgaa046

29. Radetti G, Salerno M, Guzzetti C, Cappa M, Corrias A, Cassio A, et al. Thyroid function in children and adolescents with Hashimoto's thyroiditis after l-thyroxine discontinuation. Endocr Connect. (2017) 6:20612. doi: 10.1530/EC-17-0023

30. Hollowell JG, Staehling NW, Flanders WD, Hannon WH, Gunter EW, Spencer CA, et al. Serum TSH, $\mathrm{T}_{4}$, and thyroid antibodies in the United States population (1988 to 1994): National Health and Nutrition Examination Survey (NHANES III). J Clin Endocrinol Metab. (2002) 87:48999. doi: $10.1210 /$ jcem.87.2.8182

31. Wasniewska M, Corrias A, Salerno M, Lombardo F, Aversa T, Mussa A, et al. Outcomes of children with hashitoxicosis. Horm Res Paediatr. (2012) 77:36-40. doi: 10.1159/000334640

Conflict of Interest: The authors declare that the research was conducted in the absence of any commercial or financial relationships that could be construed as a potential conflict of interest.

Copyright (๑) 2020 Admoni, Rath, Almagor, Elias-Assad and Tenenbaum-Rakover. This is an open-access article distributed under the terms of the Creative Commons Attribution License (CC BY). The use, distribution or reproduction in other forums is permitted, provided the original author(s) and the copyright owner(s) are credited and that the original publication in this journal is cited, in accordance with accepted academic practice. No use, distribution or reproduction is permitted which does not comply with these terms. 